\title{
Hispanoamérica en la política nacionalista, 1936-1939
}

\author{
Rosa María Pardo Sanz
}

La producción historiográfica sobre diplomacia y Guerra Civil se ha centrado en la actitud de los grandes estados, postergando otros escenarios de lucha diplomática y propagandística como fueron las repúblicas latinoamericanas ${ }^{1}$. Asímismo, otra de las vertientes que menos atención ha merecido ha sido la primitiva elaboración y la praxis de la diplomacia nacionalista o franquista. La consideración de tales lagunas historiográficas ha determinado el objeto de estudio de este trabajo: reconstruir los primeros planteamientos franquistas hacia Latinoamérica y determintar la importancia real que se concedió al área. Porque se sabe que el argumento de la «Hispanidad» fue utilizado en el nuevo modelo cultural nacionalista como un instrumento bélico más, pero no se ha contrastado el peso que tal elemento tuvo en la propaganda interior con lo que fue su proyección diplomática sobre las repúblicas americanas.

Por otra parte, el conjunto de iniciativas nacionalistas que se pusieron en marcha durante la Guerra Civil en Latinoamérica es revelador de otra serie de fenómenos políticos que tenían lugar en la península y que sobrepasaban las pautas estrictamente diplomáticas: la superposición de iniciativas y estructuras políticas en las tareas de propaganda; las rivalidades entre los representantes diplomáticos y los miembros de Falange

\footnotetext{
1 Vid. Falcoff, M. \& PIKe F. (Ed.), The Spanish Civil War, 1936-39. American Hemispheric Perspectives. Lincoln and London, University of Nebraska Press, 1982. PowELL, T. G., Mexico and the Spanish Civil War. Albuquerque, University of New Mexico Press, 1981. Baumann, G. G., Extranjeros en la Guerra Civil Española. Los Peruanos. Lima 1979; Goldar, E., Los argentinos y la guerra civil española. Buenos Aires 1986. Quisada, Mónica, Relaciones Hispano-Argentinas, 1936-1948. Coyunturas de Crisis. Universidad Complutense de Madrid. Facultad de Geografia e Historia (Dto. Historia de América). 1989. GonZÁlEZ, E. y Limón, F., La Hispanidad como instrumento de combate: raza e imperio en la prensa franquista durante la guerra civil española. Madrid, CSIC, 1988. NARAnso, C., Cuba, otro escenario de lucha. La guerra civil y el exilio republicano español. Madrid, CSIC, 1988.
} 
Exterior; o las pugnas entre grupos nacionalistas de distinto sesgo ideológico. América se configura como un marco privilegiado para la reconstrucción de algunos de estos procesos.

Así pues, se trata de valorar la efectividad de la política franquista durante la coyuntura bélica y también de aprehender sus consecuencias de cara a la politica americanista futura del franquismo ${ }^{2}$. El trabajo se ha estructurado en tres bloques. En el primero de ellos se bosqueja el marco general de los condicionantes internacionales y nacionales que determinaron la actividad diplomática: por una parte el contexto americano y, por otra, las imposiciones procedentes del proceso bélico interno. Un segundo conjunto temático analiza las estructuras gubernamentales y no gubernamentales que intervinieron en la planificación y ejecución de la política orientada hacia América: las instancias ministeriales, los representantes diplomáticos, las organizaciones creadas en las colonias españolas y los mecanismos de implantación de Falange. El último capítulo se encarga de recrear los despliegues propagandísticos y diplomáticos franquistas: su efectividad y las consecuencias para la politica franquista posterior hacia América.

\section{LOS CONDICIONANTES INTERNACIONALES Y LOS OBJETIVOS $B E ́ L I C O S$}

Para las naciones latinoamericanas la Guerra Civil no tenía las implicaciones estratégicas y de seguridad que para los estados occidentales; al contrario, interpretaron el tema español bajo el prisma de sus propios problemas domésticos: muchas veces más próximos a la realidad española de lo que hubiese sido deseable. De ahí que en sus respuestas a la crisis española fuese definitorio el balance de las fuerzas políticas internas en cada república. Un balance que determinó afinidades ideológicas gubernamentales mayoritariamente favorables al bando nacionalista.

En julio de 1936, el poder ejecutivo de quince de las veinte repúblicas americanas estaba ocupado por militares: sólo eran civiles los presidentes de Panamá, Costa Rica, Colombia, Chile o Uruguay (hasta 1938). A su vez, catorce eran dictaduras (Haití, Cuba, Rep. Dominicana, Nicaragua, Guatemala, El Salvador, Honduras, Ecuador, Perú, Brasil, Uruguay, Pa-

2 De hecho, este articulo se enmarca en un proyecto más amplio de tesis doctoral sobre la política franquista hacia América Latina entre 1939 y 1950. 
raguay, Bolivia, Venezuela) y cuatro más estaban dirigidas por civiles conservadores representantes de la oligarquía socioeconómica: el Panamá de Arosemena, Costa Rica con León Cortés, el Chile de Alessandri o la Argentina del general Justo.

Por otra parte, aunque en principio la dialéctica fascismo versus antifascismo no fue el móvil fundamental de la polémica sobre España en América, no se puede obviar tampoco la influencia de esta ideología sobre los líderes americanos del momento. El «nuevo orden» encontraba simpatizantes entre los dictadores militares y en grupos de la oligarquía tradicional. Unos veían en ella la reivindicación inesperada de su propio autoritarismo; los otros un posible freno para los excesos de la democratización política; e incluso sectores renovadores del ejército podian percibir modelos para remover a las oligarquías de los aparatos constitucionales ${ }^{3}$.

No es difícil vislumbrar elementos de identificación ideológica entre el bloque nacionalista español y el conjunto de dictadores o lideres conservadores y anticomunistas que ostentaban el poder al otro lado del Atlántico. Es evidente que el control oligárquico ejercido en todas las repúblicas determinó las simpatías ideológicas de muchos aparatos oficiales. Tan sólo el mexicano Cárdenas, López Pumarejo en Colombia, o el chileno Aguirre Cerda pudieron percibir una cierta afinidad política con algunas líneas de acción del republicanismo español.

Desde el punto de vista del sistema internacional, el componente decisivo en las respuestas americanas fue la coyuntura de las relaciones entre Estados Unidos y el resto de América Latina. La política de Buena Vecindad experimentaba los primeros avances e iba siendo aceptada por el resto de las naciones americanas, cuya dependencia económica y política respecto a EE.UU se acrecentaba al mismo ritmo. Este hecho suponía un creciente peso de las decisiones diplomáticas norteamericanas

\footnotetext{
${ }^{3} \mathrm{M}$. Falcoff hace hincapié en otros rasgos del fascismo apreciados por los líderes americanos: en especial su capacidad de aunar modernización, control social y valores tradicionales: FALCOFF, M., «Preface» en FALCOFF, M. \& PIKE, F., Op. cit., h. XIII-XIV. Los representantes diplomáticos ratificaban estas opiniones: «(...) La mayoria de los Jefes de Estado de América, sienten una profunda admiración por Franco, Mussolini y Hitler. Cada victoria del fascismo, la celebran como propia, puesto que estos éxitos les aseguran cada día más en sus posiciones de mando, alejando las posibilidades de que triunfen los que se les oponen. (...) Estos regimenes americanos se parecen a los fascistas, tan sólo en que son totalitarios, en el sentido de no permitir mas que un partido, pero no en que su único sostén, faltos de toda mística, es tan sólo el poder militar" en A. Pinilla a Jordana, 8-12-1938, en Archivo del Ministerio de Asuntos Exteriores (AMAE), R-1449/3.
} 
sobre el resto de las cancillerías americanas ${ }^{4}$. De ahí que la posición de Washington en el tema español terminase por resultar decisiva y marcase la tónica general en el continente. Washington se decidió por una neutralidad en la línea europea de la no intervención: ni se otorgaron títulos jurídicos a los insurgentes, ni el gobierno republicano pudo sacar partido de su status legal ${ }^{5}$.

La mayoria de las repúblicas se atuvieron a la estrategia estadounidense (casi siempre de «motu propio», en espera de alguna recompensa) o al menos procuraron no entorpecerla. La influencia norteamericana se iba a manifestar en las fechas de los reconocimientos diplomáticos al gobierno de Franco y en el retórico tratamiento del problema español, tanto en las Conferencias Panamericanas de Buenos Aires (1936) y Lima (1938), como en la SDN ${ }^{6}$.

Por lo que se refiere a los objetivos inmediatos de la incipiente diplomacia franquista se pueden resumir en tres. Por una parte, localizar la guerra asegurando la ayuda de las potencias amigas y procurando limi-

${ }^{4}$ Duroselle, J. B., La politica exterior de los Estados Unidos (de Wilson a Roosevelt). México 1965, págs. 269-275; DalLEK, R., Franklin D. Roosevelt and American Foreign Policy, 1932-1945. Oxford 1979. págs. 127-136; Gellman, I. F., Good Neighbour Diplomacy U.S. Policies in Latin America, 1933-1945. Baltimore 1979, pág. 10-11; Wood, B., La Politica del Buen Vecino. México, UTHEA, 1961.

${ }^{5}$ Semejante posición comportó una doble utilidad: permitia al Departamento de Estado exhibir una política de colaboración con las potencias europeas, mientras soslayaba el compromiso de una decantación clara en el asunto español. Si Washington pretendía convencer a las repúblicas americanas de que poseian intereses comunes -en la línea de la "Good Neighbour Policys-, no podia correr el riesgo de romper la unanimidad suscitando una polémica continental por la cuestión española. Vid. TAYLOR, F. J., (The United States and the Spanish Civil War. New York 1969) y GutTMAN (The Wound in the Heart. America and the Spanish Civil War. New York 1969) de forma parcial. Dallek, R., Franklin D. Roosevelt and American Foreign Policy, 1932-1945. Oxford 1979, págs. 127-136 y 179-80; FEE, G. W., "The Course of the United States Government Policy toward Spanish Civil War, 1936-1939", Dissertation, B. L. Cambridge University, 1955. El estudio más completo es el Traina, R., American Diplomacy and the Spanish Civil War. London 1968 (ver especialmente págs. 26 y 117). El resto de los autores se limitan a seguir esta última obra: DuRA, J., United States Policy towards Dictatorship and Democracy in Spain, 1936-1953. A Case Study in the Realities of Policy Formation. Ph. D. Berkcley. 1972, págs. 140; PIKE, F., «The Background to the Civil War in Spain and the United States Response to the War" en FALKofF, M. \& PIKE, F., Op.cit., págs. 1-48. Sobre leyes de neutralidad: GREEN, Joseph C., «Supervising the American Traffic in Arms» en Foreign Affairs, vol. 15, n. ${ }^{\circ} 4$ (1937), págs. 729-744.

${ }^{6}$ De igual forma, la tradición internácionalista latinoamericana estuvo presente en ef conflicto español: unas veces como argumento justificatorio y otras con un peso especifico fundamental. Tal fue el caso de las alusiones al Tratado Centroamericano de 1923 -que negaba el reconocimiento diplomático a los gobiernos instaurados por la fuerza- y al «Protocolo Adicional relativo a la No intervención", aprobado en Montevideo (1933). La aplicación del «Derecho de Asilo" fue otro ejemplo: RuBı, J., Asilos y canjes durante la guerra civil española. Barcelona, Planeta, 1979. 
tar, en lo posible, el apoyo extranjero al enemigo. El segundo fin era contrarrestar la actividad republicana en el exterior y el último, conquistar un status jurídico como estado que proporcionara a los sublevados una cierta aceptación en el sistema internacional ${ }^{7}$.

En el continente americano, donde las cuestiones conectadas con la actividad militar tuvieron menos relevancia, la consecución del «reconocimiento diplomático" ("de facto" o "de jure») se convirtió en prioridad fundamental para neutralizar la acción republicana. Era preciso conseguir ciertas prerrogativas jurídicas a fin de poder emitir pasaportes, ejercer las funciones consulares, defender el uso de la bandera bicolor, organizar actos de propaganda nacionalista o mantener contactos con las autoridades locales. Resultaba fundamental para el funcionamiento normal de las actividades bilaterales: del comercio y de la protección de los intereses españoles. Sin el requisito del reconocimiento, sólo las autoridades republicanas podian disfrutar de tales atribuciones como agentes diplomáticos de un estado soberano ${ }^{8}$.

Sin embargo, las consignas enviadas en 1938 describian dos niveles de actuación de la política del Nuevo Estado en América. Por una parte, la labor estrictamente diplomática y de propaganda, en busca de un reconocimiento jurídico. Por otra parte, la acción sobre las colonias españolas: trabajando por su protección, unión y comunícación con la España Nacional. Para el primer cometido, los instrumentos aconsejados se cifraban en la utilización de las influencias y amistades personales; es decir, de las "conexiones privadas con los círculos oficiales y con las personalidades del país de ideas simpatizantes con el Movimiento". El agente oficioso debía «hacerse amigo en forma absolutamente privada de las principales autoridades y, bajo cuerda, sin comprometerlos, obtendría de ellos las medidas convenientes en favor nuestro". Se desechaban métodos más directos, como podian ser las polémicas en la prensa; descartando sobre todo la participación del representante diplomático con su firma en los medios de comunicación. La propaganda, se dice, no debia

\footnotetext{
7 "G. Vidal (jefe del Servicio de Política y Tratados) a Jordana, 28-1-1939» en AMAE, R$834 / 33$.

${ }^{8}$ Sobre estos problemas jurídicos, vid. Jessup, Philip C., "The Spanish Rebellion and International Law» en Foreign Affairs, vol. 15, n. ${ }^{\circ} 2$ (1937), págs. 260-279. También en PADELForo, Norman J., International Law and Diplomacy in the Spanish Civil War. New York 1939. En Burgos la "Asesoria Jurídica del Ministerio de Asuntos Exteriores", a cargo de Pedro Cortina Mauri, elaboró algunos documentos al respecto: «Normas del derecho internacional para la guerra civil» en AMAE R-834/33 y YaNGUAS MESSIA, J., Beligerancia, no intervención y reconocimiento. Madrid, Editora Nacional,1938.
} 
ser hecha públicamente por el Representante, sino por oradores enviados al efecto desde la España Nacional ${ }^{9}$.

El estatuto de agentes oficiosos forzaba a los representantes nacionalistas a una extremada prudencia, a fin de evitar desautorizaciones e incluso expulsiones. Se ordenaba una «total disciplina» a las leyes y las autoridades del país a fin de no poner en peligro la ya compleja situación de estado no reconocido. Por consiguiente, las restricciones legales que sufrían los representantes nacionalistas no hacian sino reforzar consideraciones ideológicas y fórmulas muy clásicas de «diplomacia».

El segundo vector de la acción diplomática tenia como objeto las colonias españolas de emigrantes en América. Supuso la reproducción en el hemisferio occidental del proceso de la unificación politica que estaba teniendo lugar en España. El objetivo a corto plazo fue centralizar los esfuerzos de propaganda y recaudación. Lo que se pretendía después era sentar las bases de una acción a medio y a largo plazo que recuperaba proyectos reiteradamente expuestos en los decenios anteriores, por los defensores de un Hispanoamericamo práctico, pero ahora con un modelo y un lenguaje fascistas. Esta última vertiente explica la aparición en escena de Falange Exterior como una estructura de poder paralela al engranaje del servicio diplomático y no siempre en armonía perfecta con él.

\section{PLANIFICACIÓN POLITICA Y AGENTES NACIONALISTAS EN AMERICA}

En el «aparato diplomático central», los hombres encargados de la política americana fueron: Yanguas Messia y Sangróniz (hasta octubre de 1936); F. Serrat y M. A. Muguiro en la Secretaria de Relaciones Exteriores, hasta la creación del Ministerio a principios de 1938. En el nuevo ministerio, la cadena informativa y decisional para las cuestiones americanas pasaba por el jefe de la Sección de Ultramar (R. Pujadas), la Jefatura de Política y Tratados (J. de Rojas Moreno), el subsecretario (Espinosa de las Monteros) y finalmente por el ministro Gómez Jordana ${ }^{10}$.

${ }^{9}$ Instrucciones para el ejercicio de la Representación, 18-6-1938, en AMAE, R1003/1.

${ }^{10} \mathrm{Se}$ han consultado expedientes personales depositados en el AMAE: leg. P-294/21.890, $\mathrm{P}$ 346/24.388, P-250/14.621, P-458/33.720, P-539/35.956. Algunos datos sobre la trayectoria de Francisco Gómez Jordana en: Tuseli., J., «La Junta Técnica de Estado», en La Guerra Civil. Historia 16, n. ${ }^{\circ} 7$ (1986), págs. 76-88. 
Excepto estos dos últimos (de acreditada carrera militar), el resto pertenecian al cuerpo diplomático. Algunos, como Yanguas y Sangróniz., habían ocupado importantes puestos en el Ministerio de Estado durante la dictadura de Primo de Rivera. Como ministro, Yanguas habia sido promotor de un relanzamiento del Hispanoamericanismo; aunque su corto mandato le impidiera ponerlo en marcha. De la misma forma, Sangróniz fue el gran sintetizador de las aportaciones regeneracionistas y tradicionalistas en el campo americanista: su famoso proyecto de «Expansión Cultural» estaba orientado de manera preferente hacia América. Ambos, como Muguiro y el propio Franco, habian estado ligados al grupo de Acción Española. Una adscripción ideológica que se traslucía desde 1937 en las declaraciones y discursos del general relativos a Hispanoamérica. Todos ellos, como también Jordana, Rojas o Vidal, habian prestado sus servicios en el Norte de África: la mayoria durante la etapa primorriverista. Finalmente, tanto Rojas como Jordana y Sangróniz habian tenido problemas con las autoridades republicanas por su colaboración con el régimen anterior. Asi pues, existía una clara homogeneidad en las personalidades del nuevo Ministerio, extrapolable al propio Caudillo: como militar africanista, antirrepublicano y conectado a Acción Española.

Sin embargo, quienes pudieron dar continuidad a la política hispanoamericanista fueron hombres como J. Rojas Moreno (director General de Política durante la República) y, sobre todo, José del Castaño Cardona, último jefe de la Sección de Ultramar antes del Alzamiento y, por tanto, uno de los hombres mejor informados de la realidad americana. Castaño, desde su cargo como delegado Nacional del Servicio Exterior de F.E.T. y de las J.O.N.S., se erigió en una autoridad paralela con gran influencia sobre las actividades nacionalistas en el campo de la propaganda y la acción sobre las colonias españolas ${ }^{11}$.

Respecto al «cuerpo diplomático», en julio de 1936 los cinco embajadores y otros seis representantes acreditados en América se declararon

${ }^{11}$ Era un diplomático desde 1917 Tánger. Estaba especializado en Norte de África -como muchos otros protagonistas de la diplomacia nacionalista del momento-y en los asuntos americanos. Desempeñó la Jefatura de la Sección de Política de Ultramar y Asia desde 1933 hasta julio de 1936. Los motivos de su elección (octubre de 1937) como Delegado del Servicio Exterior no están claros, ya que no es probable que estuviera afiliado a Falange; más bien era notoria su amistad con Sangróniz y Muguiro. A tenor de estos antecedentes, su perfíl ideológico estaría más próximo a los monárquicos y conservadores de la Secretaría (e incluso al propio Jordana) que a su antecesor en el cargo, Ximénez de Sandoval. Su personalidad marcó, en gran medida, la evolución subsiguiente de las Falanges americanas. Fue relevado en mayo de 1939 y quedó como excedente forzoso hasta que fue enviado de cónsul a Manila; aun cuando el cargo que él deseaba fuese la embajada en Alemania. Fue recuperado por Artajo para la Dirección General de África y Próximo Oriente en 1945. Expediente personal, en AMAE, R-472.33777. 
leales al gobierno republicano. Sólo los jefes de sedes diplomáticas menores (como la paraguaya o las centroamericanas) y de la peruana proclamaron su fidelidad a Burgos. Al frente de las representaciones oficiosas nacionalistas en las principales capitales americanas, permanecieron durante casi toda la guerra secretarios de embajada que previamente habian presentado su dimisión al Ministerio de Estado arrogándose la representación del nuevo gobierno nacionalista. El resultado fue la escasez de personal (más grave en los consulados) y la disminución de su categoría profesional, ya que algunos de los agentes oficiosos ni siquiera pertenecian a la carrera diplomática ${ }^{12}$.

La falta de medios humanos que se esconde tras estas restricciones es una muestra más de la escasa atención concedida a América durante la guerra. Este hecho se comprueba también en la reducción de presupuestos. Apenas se dispuso del 25 por 100 de lo presupuestado para 1936; agravada la situación por enormes desequilibrios a favor de sedes insignificantes como las centroamericanas, porque se decidió que sólo los agentes oficiales (en países que reconocieran al gobierno de Franco) recibirian sus asignaciones completas. Mientras, los agentes oficiosos (la mayoria) apenas percibían el 50 por 100 o menos de las consignaciones ${ }^{13}$.

Por lo que se refiere a los hombres ${ }^{14}$, la mayoria de ellos habian dado sus primeros pasos diplomáticos durante la dictadura primorriverista. Habian servido en un contexto interamericano (años veinte) muy enrarecido por el intervencionismo norteamericano, bien distinto al clima creado a partir Política de Buena Vecindad que se desarrollaba de forma paralela a la guerra española. Todos ellos coincidían por su unánime antiliberalismo. Sus juicios acerca de los regímenes políticos americanos o del Nuevo Estado español rezuman un fuerte conservadurismo, con incipientes matices corporativistas o fascistas en algunos individuos, aun cuando la identificación con Italia y Alemania no fuera muy frecuente. La palabra

${ }^{12}$ AMAE, R2571 BIS /4-5. Hacia julio de 1936 las representaciones españolas en América Latina estaban constituidas en teoria por cinco embajadas, doce legaciones y veintisiete consulados.

${ }_{13}^{13}$ A. Fernández de la Mora a Jordana, 9-9-1938 y 10-9-1938, AMAE, Leg. R-2136/6. También AMAE, Leg. R-2136/2-11.

${ }^{14}$ M. Espelius y M. Espinós en Cuba; Dionisio Trigo, cónsul en Puerto Rico; R. Pujadas y Augusto ibáñez en México; Ojeda y Brooke en Costa Rica; Buigas de Dalmau y Ortuño, secretario en Honduras, Salvador y Nicaragua; López Escobar y Triana en Guatemala; Arenzana en Panamá; Sangróniz en Venezuela; Avilés y Tiscar (Perú); José Tibau (Ecuador); Antonio Pinilla (Perú y Bolivia); Formerio González (Bolivia); E. Prous (Paraguay); José de Cárcer (Brasil); F. de Amat y Juan P. Lojendio en Argentina; Pérez de Rada y Tomás Súñer en Chile; R. Soriano en Uruguay. 
mágica para ellos era "orden»: disciplina en lo político, social, religioso y militar. Su status diplomático (y la adscripción nobiliaria, en varios casos) les proporcionaba una acentuada conciencia de pertenecer a la clase de los mejores. Las masas no eran, para algunos, mas que turbas ignorantes, ganadas por la propaganda marxista. Su desprecio por la opinión pública democrática era absoluto y su juicio acerca de los emigrantes españoles no era menos negativo en muchos casos. ${ }^{15}$. Tal ideología, impregnada de un fuerte espíritu de cuerpo y de clase, iba a modular la percepción acerca de los regímenes políticos americanos; la elección de los sectores sociales sobre los que actuaría la diplomacia y la propaganda, así como la política a seguir con la colonia española.

Por último, las "colonias españolas» en América constituyeron a la vez un agente y un vector de la política exterior: fueron actores y víctimas, al mismo tiempo. La guerra significó para los emigrados la ruptura de comunicaciones, dificultades legales, comerciales y enfrentamientos políticos; a la par que, como grupo, desempeñaban el papel de agentes propagandisticos directos e indirectos en las sociedades anfitrionas del nuevo continente.

La división de las colonias españolas fue inmediata. Las tomas de posición dependieron, en general, de la situación socio-económica de los emigrantes, de su filiación política y de su pertenencia a minorías nacionalistas y regionalistas concretas. En las repúblicas con mayor número de españoles las simpatías prorrepublicanas fueron mayoritarias: tal fue el caso de Argentina, Brasil, Cuba, Chile o Venezuela. En Uruguay y México el porcentaje de los partidarios de ambos contendientes fue más parejo. En las repúblicas con colonias por debajo de los 4.000 españoles, sólo una minoria se decantó amiga de la República: así pasó en Bolivia, Ecuador, Perú, Paraguay, Honduras, Costa Rica y Nicaragua. Hubo paridad en Guatemala, Panamá y El Salvador. En general, las inclinaciones de la élite económica fueron semejantes, excepción hecha de personalidades de orígen vasco y catalán. En el caso de pequeños comerciantes

\footnotetext{
${ }^{15}$ Como ejemplo: Lojendio a Jordana, 2-2-37 en AMAE, Leg. R-1003/0: "Las clases modestas de la colectividad son (...) hombres de acción y de escasa cultura, sin conocer no ya nuestra Historia sino hasta España, un poco agriados porque ven triunfar a algunos de nuestros compatriotas a los que juzgan iguales cuando no inferiores, resentidos en cierto modo con España porque la necesidad les obligó a emigrar, en un ambiente en que las diferencias de clase social aunque profundas no salen a la superficie como en España, sin otro alimento espiritual que la lectura de periódicos que no hacen más que desorientarles, están entregados por completo a la causa de los marxistas españoles creyéndose muchos de ellos de buena fe que defienden la democracia. Y ¿cómo no va a agradarles la democracia, tal como ellos la entienden, si es de la única forma que pueden lograr una igualdad que nunca podrán conseguir por sus propios méritos?».
} 
o trabajadores independientes, su actitud varió según el propio clima político que se vivía en las repúblicas anfitrionas; dado que, en su carácter de hombres públicos (tenderos minoristas, etc.), temieron por la suerte de sus negocios en caso de represalias. La citada escisión de la colonia tuvo su reflejo en sociedades y asociaciones, donde los enfrentamientos entre partidarios de uno u otro bando llegaron a adoptar tintes dramáticos: maniobras sucias en las elecciones de las Juntas de Gobierno, expulsiones...

Desde el punto de vista organizativo, en el verano de 1936 surgieron diversas asociaciones (Ilamadas Juntas o Comités Nacionalistas) como instrumentos centralizadores del auxilio a los sublevados. A veces nacieron de forma casi espontánea, otras a partir de instituciones españolas preexistentes o como respuesta a la incitación del representante diplomático nacionalista que precisaba alguna plataforma para actuar. Su finalidad primigenia fue realizar subscripciones y recoger donativos o ayuda material; aunque en realidad sus tareas fueron más amplias, ya que hasta la constitución real de las filiales falangistas, se hicieron cargo de funciones propagandísticas e incluso de la representación oficiosa de Burgos ${ }^{16}$.

En la primavera de 1937, las actividades de las Juntas Nacionalistas coincidian con la presencia de otras entidades politicas organizadas, filiales de Renovación Española (en Argentina y México), la Comunidad Tradicionalista (en Uruguay y Argentina), de la C.E.D.A (México y Cuba) y de Falange ${ }^{17}$. En el caso de F.E.-J.O.N.S., las primeras secciones se crearon en Chile, Argentina, Cuba, México y Uruguay. En sus comienzos presentaron graves problemas de liderazgo: sus jefes se vieron envueltos en escándalos de malversación de fondos y abuso de autoridad que dañaron la imagen de las nacientes organizaciones ${ }^{18}$.

${ }^{16}$ Algunos ejemplos en: «U. Pérez de Rada a Jordana, 18-1-1938, en AMAE, R-1003/10; Sebastián Naranjo a Jordana, 28-9-1938, en AMAE, R-1003/6; J. Arenzana a la Dirección Política, 4-6-1937, en AMAE, R-1005/7; también AGA.AE Caja 10079.

${ }_{17}$ Sobre esas organizaciones: QuiJada, M., Op. Cit., pág. 230; Goldar, G., Op. Cit., pág. 118; Programa de "Acción Social hispano-Cubana. Por Cuba y por España», en AMAE, R1003-17; A. Ibáñez a Jordana, 1-8-1938 y El jefe de F.E.T. y de las J.O.N.S. a J. del Castaño, 24-12-1937, en AMAE, R-1009/2.

${ }_{18}$ Ver diversos informes en AMAE, R1009/2. También: UnRutiA, F. de, La Falange Exterior. Santander 1938. (sin paginar). FOXA, A. de, "Las organizaciones de la Falange Exterior, reflejo vivo de la Vida Española", en jArriba España! (La Habana) 18-3-1939 apud, NARANuo, C., Op. cit, pág. 13; González Calleja, Eduardo, «El Servicio Exterior de Falange. Consideraciones previas para su investigación", en Actas del Coloquio sobre Proyección Mediterránea y Atlántica de la España Contemporánea. Madrid, Universidad Complutense 1988 (en prensa). 
Paralelamente, desde Burgos, la visión de los militares (incluido Jordana) acerca de cúal habia de ser el papel de los españoles residentes fuera de las fronteras era sencilla: las colonias españolas (como «islotes de solar patrio") debían participar en el esfuerzo bélico. El diplomático, a su vez, estaba obligado: a su defensa, a su control y a informar acerca de sus problemas y posibilidades ${ }^{19}$. De ahí que a partir de mediados de 1937, se perfilara la necesidad de coordinar todos los esfuerzos, dispersos y más o menos espontáneos, nacidos entre las colonias. Para ello se superpuso una nueva estructura, Falange Exterior, que debía realizar en América la misma construcción política que desde el decreto de Abril de 1937 se intentaba imponer en la península: la «Unificación». El modelo fascista era evidente: se trataba de que Falange obtuviese la hegemonía en las organizaciones de los emigrantes españoles, a fin de que las colonias - con una sólo identidad política - se erigieran en un «elemento de fuerza" que pudiese auxiliar y cooperar en la política exterior como grupo de presión en el país de residencia. Estos planteamientos fueron aprovechados por los conductores del Nuevo Estado (desde abril de 1937) con objetivos bien concretos en América. Se podia acometer el proceso de unificación de las colonias españolas homogeneizando el complejo entramado de Juntas, Comités y otros organismos con la base formal de la antigua FET y de las JONS. Si se lograba, sería la mejor táctica para incorporar a las colonias al esfuerzo bélico, consiguiendo así un instrumento pseudo-oficial que pudiese desarrollar las tareas de propaganda y captación sin arriesgar la frágil posición legal de los diplomáticos nacionalistas ${ }^{20}$.

Para afrontar la labor se nombró Delegado Nacional del Servicio Exterior de FET y de las JONS (en octubre de 1937) a José del Castaño. El objetivo de partida era reorganizar las filiales de Falange ya existentes y fundarlas allí donde no hubieran sido creadas. Para ello, se enviaron jefes falangistas de la península en el otoño-invierno de 1937 y 1938: Duyos, A. Atalaya, A. Martín Cotano (Jefe de Prensa y Propaganda de Marruecos) y G. Albareda. La evolución "deseable», sin enfrentamientos, se producía cuando las Juntas Nacionalistas se disolvían con el fin de pasar a integrar una Delegación falangista. La fórmula permitía la supervivencia de los mecanismos de recaudación (ahora enmarcados en el Servicio de Auxilio Social) y conseguía articular las dos estructuras organizativas; aunque se desposeía a la Junta de lo que pudieran ser atribuciones de matiz politico

\footnotetext{
${ }^{19}$ El Ministro de Asuntos Exteriores a los representante del Estado Español en Paraguay, junio de 1938, en AGA.AE Caja 12026.

${ }^{20}$ Circular n. 3 FET y de las JONS. Delegación Nacional del Servicio Exterior, 30-6-1937, en AGA.AE Caja 10079.
} 
o propagandístico. Sin embargo, desde el mismo otoño de 1937, comenzaron a estallar graves disensiones que involucraron a los nuevos grupos falangistas, a los representantes diplomáticos nacionalistas y a las asociaciones (políticas o no) de las colonias españolas. Se daba el caso de que en algunas repúblicas - Argentina, Perú o México- se presentaban varios de estos conflictos a la vez ${ }^{21}$.

Muchas Juntas no se resignaban a perder protagonismo con tanta docilidad y se resistieron a la integración en Falange. Los serios incidentes ocurridos en Brasil dieron pie a la intervención directa de Franco en el sentido prescrito por la Circular n. 39 : abstenerse de forzar la integración o disolución de las Juntas, que seguirían funcionando hasta el final de la guerra. Si bien, Falange debía asegurarse una adecuada representación en la directiva de las mismas ${ }^{22}$.

En ocasiones, la propia dinámica social de cada colonia -con la presencia de verdaderos "caciques»- obligaba a una abierta competencia por el liderazgo político. Otras veces, las agresivas proclamas de los falangistas chocaban con la idiosincrasia conservadora más tradicional de una parte de la colonia. Casi siempre, los enfrentamientos tenían sus raíces en las diferencias políticas o de competencias entre los representantes y los jóvenes mandos de FET y de las JONS. La existencia paralela de un jefe político y una autoridad diplomática, suponía una duplicación de potestades, a pesar de las reiterativas órdenes recordando la supremacia del Jefe de misión diplomática como representante del Estado ${ }^{23}$.

Argentina fue escenario de pugnas significativas a este respecto. $\mathrm{Ni}$ siquiera el relevo de su directiva en 1937, consiguió hacer mejorar la opi-

${ }^{21}$ Prous a Jordana, 23-12-1938, en R-1003/1; Castaño a Muguiro, 26-10-1937, en AMAE, R-1009/2. VEGA, Bernardo, Nazismo, Fascismo y Falangismo en la República Dominicana. Santo Domingo 1985, págs. 355-6; Circular n. 39 . José del Castaño. Delegación Nacional de Falange Exterior, 31-12-1937, en AMAE, R-1009/2. Jefe territorial de Uruguay a R. Soriano (agente oficisioso), 10-6-1937, en AGA.AE Caja 10079. El problema de los nacionalistas en Brasil: Informe politico y económico de Brasil (J. de Cárcer a Jordana), 15-10-1938, en AMAE, R-1572/55.

${ }^{22}$ Circular n. 39 . José del Castaño. Delegación Nacional de Falange Exterior, 31-12-1937, en AMAE, R-1009/2. Por una parte, el contenido de la circular determinaba con claridad que las Juntas exclusivamente iban a mantener la función de recaudar fondos; dando por sobrentendido que eran enajenadas de cualquier otra finalidad política. Además, el partido sólo tenía jurisdicción para absorber a las agrupaciones tradicionalistas, argumento que jugó a favor de las otras asociaciones: Jefe territorial de Uruguay a $R$. Soriano (agente oficisioso), 10-6-1937, en AGA.AE Caja 10079. El problema de los nacionalistas en Brasil: Informe politico y económico de Brasil (J. de Cárcer a Jordana), 15-10-1938, en AMAE, R$1572 / 55$.

${ }^{23}$ Circular n. $29,18-12-1937$, en Boletín del Movimiento de FET y de las JONS, (Salamanca), $n . \circ 12,15-1-1938$. Esta orden fue reiterada a lo largo de 1938, lo que da idea de la continuidad de los recelos. 
nión de la colonia acerca del partido o aumentar el número de afiliados. El agente diplomático, J. P. Lojendio, y los jefes regionales del Servicio Exterior de Falange se intercambiaban acusaciones ante sus respectivos superiores. Los Falangistas denunciaban la falta de atribuciones otorgadas a Falange y la competencia de otras entidades nacionalistas con la complicidad del representante oficioso franquista. Por su parte, Lojendio acusaba a los nuevos líderes falangistas de practicar una demagogia que no se acomodaba a la idiosincrasia de la colonia española. El asunto llegó a las más altas esferas de Falange: el Secretario General, Raimundo Fernández Cuesta dirigió una misiva a Jordana sugiriendo la conveniencia de que las organizaciones argentinas pronacionalistas (Renovación Española, Acción Española, Comunión Tradicionalista y Legionarios de Franco) fuesen despojadas - a favor de Falange - de funciones ajenas a la de recaudar fondos y se refundieran en una apolítica «Junta Nacional Española Recaudadora». Sin embargo, la decisión del Ministro se acomodó al informe del jefe de sección, R. Pujadas. A su juicio, la disolución de tales asociaciones era inútil y contraproducente para los intereses nacionales: en mayo de 1939 todas ellas seguían laborando de manera independiente ${ }^{24}$.

En cualquier caso, se produjo una cierta disrupción entre las formulaciones planteadas en el Ministerio de Exteriores (Jordana) y la propia dinámica falangista. Del Ministerio llegaban órdenes administrativas, mientras que las circulares de Falange eran verdaderos programas de acción. Castaño había asumido el discurso y los planteamientos fascistas que recreaban toda una mística acerca de los nacionales en el extranjero; aunque tampoco se alejaban del papel otorgando al emigrante en los programas elaborados en el Ministerio de Estado a lo largo de los años veinte $y$ treinta.

No obstante, Castaño estableció una gradación de prioridades: durante la guerra, Falange se aplicaria en centralizar las actividades relacionadas con el esfuerzo bélico: la organización (unificación) y la propaganda (o mejor, contrapropaganda). De ahí que los primeros servicios que se instalaban eran las secciones de encuadramiento (masculina, femenina y flechas), los mecanismos de recogida de fondos y el servicio de propaganda. Simultáneamente se prepararia el camino a perspectivas más amplias de actuación en la postguerra. Para esa segunda fase se preveía profun-

\footnotetext{
${ }^{24}$ Ver: A. Atalaya y Eugenio Montes a J. Castaño, 25-1-1938, AMAE, R-1009/2; J. P. Lojendio a Jordana, 9-2-1938, en AMAE, R-1002/14; R. Fernández Cuesta a Jordana, 11-2-1938, Pujadas a Jordana, 5-3-1938, Lojendio a Jordana, 12-4-1938 en AMAE, R-1009/2 y Lojendio a Jordana, 20-5-1939, en AMAE, R-1002/14.
} 
dizar en la obra politico-social de Falange: con un estricto control político, con «la conquista de los centros españoles» y con la trasposición a las colonias de todos los instrumentos de encuadramiento político y de acción social: Delegación de sindicatos, de Auxilio Social, Departamentos de Educación y Formación Juvenil y toda una serie de iniciativas para dignificar y unificar a las colonias.

El hecho de pertenecer a la carrera diplomática, su constante comunicación con Jordana y el conocimiento de la realidad española en América que poseía Castaño se reflejó en la prudencia de sus circulares a Falange. En todo momento recomendó una actuación muy medida, en el respeto a la legalidad y rechazó las medidas más coactivas propugnadas desde América, posponiendo el programa maximalista. Se dictaron normas rigidas respecto a la necesidad de mantener la estructura falangista en el marco de la legalidad de cada república. La prohibición de milicias y las disoluciones de Falange (desde 1938) en aquellos paises donde fueron prohibidas las agrupaciones políticas extranjeras dieron buena muestra de tal intención. Lo mismo que las consignas dictadas a los representantes y a los inspectores de Falange desde mediados de 1938, cuyo contenido se cifraba en conseguir la integración pacífica de las instituciones de la colonia en un «Hogar» común o Casa de España. A veces, como en el caso de Puerto Rico, Perú o Venezuela, tal solución se propugnó incluso como alternativa a la unificación de dichas instituciones en Falange ${ }^{25}$. No obstante, la evolución y logros de Falange variaron mucho de una república a otra ${ }^{26}$.

\section{LA ACCIÓN PROPAGANDISTICA}

"Creo urgentisimo que se organice nuestra propaganda con base más sólida; que se tengan radios que se oigan desde acá, lo que no

25 «M. M. Lojendío a Jordana, enero de 1938, en AGAAE Caja 9352. Castaño a Espinosa de los Monteros, 30-10-1938, en AMAE, R-1009/2. También en la Circular 33 (21-5-1938) en Boletín del Movimiento de FET y de las JONS, (Salamanca), n. ${ }^{\circ} 22,15-6-1938$; Alejandro Villanueva a J. del Castaño, 11-7-1938, en AMAE, R-1009/2; J. A. Sangróniz a Jordana, 14-21939, en AMAE, R-1005/17. Como señalaba en la Circular n. ${ }^{\circ}$ 39: "La labor de unificación de nuestras colectividades en el extranjero, especialmente en América Española, ha de realizarse gradualmente y con mucho tacto ya que, de no hacerlo así, se correria el riesgo de que se produjesen efectos contrarios a los que nos proponemos lograr y la desunión y la pugna entre los elementos constitutivos de nuestras colectividades".

${ }^{26}$ Por lo que respecta a la afiliación, los representantes nacionalistas contabilizaban en 1938 unos 4.000 afiliados para Chile, Argentina y Cuba; 1.000 en México y otros tantos en Uruguay: AMAE, R-1009/2 y AGAAE, Caja 9346. 


\begin{abstract}
sucede con las radios españolas (...) y que se contrarreste con sistemas similares la formidable propaganda roja, que desde hace tiempo, con el cinismo y la impudicia que le caracterizan se presenta como defensora de la Independencia de España, de la Libertad, de la Democracia, y hasta de la Religión católica, que es el colmo !!! Nuestra propaganda es "deficiente" y de corto vuelo y ya la guerra europea demostró la enorme influencia en el mundo de la propaganda aliada enfrente de la inocencia germánica. Ahora se está repitiendo algo similar; ganamos las batallas en el territorio español y las perdemos en el mundo por falta de elementos de lucha en las "mentes sencillas y crédulas" de las gentes que son la casi totalidad de los bípedos implumes" ${ }^{27}$.
\end{abstract}

El juicio de este representante puede dar idea del tono general de la propaganda Nacionalista en América: escasez de medios, de planificación y un cierto relegamiento del inmenso campo de acción que constituía la opinión pública. Los esfuerzos franquistas se limitaron a una estrategia defensiva, tratando de neutralizar los avances republicanos que se reconocian exitosos en este terreno.

Por una parte, las representaciones no recibian fondos y la propaganda se sufragaba enteramente con los donativos de la colonia. Tampoco se disponía de una agencia periodística propia, ni de una mínima infraestructura radiofónica y cinematrográfica. A las diferencias logísticas, se añadieron la desorganización en el esfuerzo y la falta de planificación. En teoria, la propaganda política dirigida a los españoles en ultramar debía ser el cometido de Falange; mientras que el servicio de prensa y propaganda estatal debía captar a la opinión pública del pais anfitrión; todo ello con la coordinación del diplomático de turno acreditado en aquel país. En la práctica, hubo múltiples combinaciones, pues se superpusieron y entrecruzaron las iniciativas de los diversos organismos nacionalistas: órganos de prensa y propaganda precariamente ideados por los representantes diplomáticos, las publicaciones de las filiales falangistas y de otras organizaciones nacionalistas, las misiones político-culturales, la propaganda de periódicos americanos ideológicamente afines, etc. Una amalgama de esfuerzos dificilmente coordinables y un tanto desasistidos desde Burgos y Salamanca.

Sólo cuando en 1938 Serrano controló también la Delegación Nacional de Prensa y Propaganda ${ }^{28}$, llegaron órdenes para que el Delegado de

${ }^{27}$ F. González a Jordana, 29-8-1938, AMAE R-1003/1.

${ }^{28}$ La primera Delegación de Prensa y Propaganda (al igual que la inicial Comisión de Cultura y Enseñanza de la Junta Técnica) estuvo controlada por monárquicos alfonsinos: la plana mayor de Acción Española contra la que se desató la rivalidad de Serrano Súñer. 
Prensa de FET y de las JONS asumiera las funciones simultáneas como Delegado de Prensa y Propaganda del Estado (o viceversa) y para que se crease en cada república una única «Oficina de Prensa y Propaganda», siguiendo el modelo de las constituidas primero en Paris y después en Buenos Aires ${ }^{29}$.

En América hubo tres enclaves destacados: Nueva York, Argentina y Cuba. Los dos primeros tenían como responsable final al representante diplomático (J. F. Cárdenas y L. M. Lojendio), mientras que el cubano dependia de las instancias falangistas. Desde la delegación diplomática oficiosa de Buenos Aires, J. P. Lojendio organizó la primera «Oficina de Prensa y Propaganda (OPYPRE)», a cargo de un agregado de prensa (J. 1. Ramos). Editaba folletos y libros, la revista Orientación Española, un Boletín de Prensa y actuaba como centro distribuidor de prensa y propaganda para toda Sudamérica. Se instalaron oficinas similares en Chile y Uruguay: desde ellas se dirigia el diario oficial, se patrocinaban programas de radio en emisoras locales y se editaban boletines. En las colonias pequeñas, la propaganda era supervisada por el agente diplomático en funciones con la colaboración de los mandos falangistas ${ }^{30}$.

Las veintidós publicaciones editadas por las organizaciones de FET y de las JONS; los periódicos y revistas de asociaciones desvinculadas de Falange y los boletines editados por las representaciones diplomáticas (veinte) tenían una reducida tirada. De manera que el peso decisivo de la propaganda escrita fue sobrellevado por los periódicos de tendencia conservadora que apoyaron la causa nacionalista; por las publicaciones religiosas o por aquellos diarios subvencionados gracias a la propaganda insertada por comerciantes españoles.

A estas iniciativas habría que añadir la colaboración de las organizaciones fascistas y nazis establecidas en América, que asistían a los actos propagandisticos y apoyaban a través de sus medios de prensa; además de los contactos y del asesoramiento proporcionado en temas organiza-

Gonzalez Calleja, V. E., “La prensa falangista y la prensa del Movimiento y del Estado: consideraciones sobre su origen y desarrollo", en Segundo Encuentro de Historia de la Prensa. Lejona, Facultad de Ciencias de la Información, 1988. Al parecer, en la pugna desatada por el control de la propagarida, Serrano introdujo en la Delegación a antiguos cedistas. Precisamente uno de ellos, Ibáñez Martín, pudo ser el encargado (a las órdenes de J. Pabón) de la propaganda hacia América: GARRIGA, R., Las relaciones secretas entre Franco y Hitler. Buenos Aires 1965, pág. 20.

${ }^{29}$ L. M. Lojendio a J. A. Martín Cotano, 18-4-38, en AGAAE Caja 9346 y 10079; Memoria sobre los Servicios Españoles de Prensa y Propaganda en París. La propaganda española en Francia durante la Guerra Civil. en AMAE, R-834/33

${ }^{30}$ J. P. Lojendio a Jordana, 9-2-1938, en AMAE, R-1002/14. También París y Buenos Aires eran los nódulos fundamentales de la red propagandistica republicana. 
tivos. Sin embargo, no existió un acuerdo general en el sentido de desarrollar una acción de conjunto en América. Se aceptaba que era más conveniente "continuar desarrollando una acción española individual, teniendo en cuenta la gran simpatia que por herencia inspira España». Se concluyó que, por el contrario, perjudicaría una acción coordinada con las futuras potencias del Eje ${ }^{31}$.

Las manifestaciones propagandísticas preferidas fueron las ceremonias de carácter festivo-político-religioso que se montaban en centros culturales, religiosos o locales sociales de la colonia, en torno a diversos eventos históricos o políticos, haciendo uso de la propaganda oral $\mathrm{e}$ invitando a la colonia adicta y a las personalidades nacionales más destacadas por su simpatía hacia la causa nacionalista. Eran las fiestas de «Plato Único», funerales por los Caídos, la fiesta del Dos de mayo, el versario del Alzamiento, el Día de la Raza. Siempre con algún oficio religioso al que asistía el nuncio o el obispo y que adquiría matices políticos evidentes por la presencia de uniformes y banderas falangistas o de los representantes diplomáticos de Italia o Alemania ${ }^{32}$. El mecanismo más elaborado de propaganda lo constituyeron las llamadas «misiones culturales», con el envío de figuras destacadas del nuevo régimen como conferenciantes y propagandistas, la mayoría próximos a Acción Española ${ }^{33}$.

Semejantes despliegues propagandísticos reflejaban perfectamente los rasgos ideológicos del nuevo «modelo cultural» que se estaba cons-

${ }^{31}$ En palabras del representante en Brasil: «Nunca podriamos, de forma alguna, hipotecar nuestra supremacía cultural, ni una legitima política de expansión comercial y acercamiento espiritual" en José de Cárcer a Jordana, 24-11-1938, en AMAE, R-1008/1. R. Soriano a Jordana, 8-8-1938, en AMAE, R-1005/16.

32 «El día de ayer, nuestra Fiesta Nacional, tuvo lugar en esta capital un funeral, que hice celebrar en la Iglesia de San Francisco, en sufragio de los que dieron su vida por España. La ceremonia fue solemne. Daban guardia de honor al catafalco, envuelto en la bandera Nacional y ofrendas florales, jóvenes falangistas en uniforme y delegados de las juventudes del Facio e Hitleriana (sic). A la cabeza de las organizaciones del partido y coIonias italiana y alemana, estaban sus Ministros y personal de ambas Legaciones. Nuestra Falange, con sus secciones y banderas, asistió con la camisa azuł. La concurrencia fue numerosa, de 800 a 1000 personas, entre colonia española, italiana y alemana, personalidades extranjeras y guatemaltecas y público en general. Muchas señoras. El Arzobispo de Guatemala presidía al clero. Se tocó la marcha Nacional al alzar y la alocución estuvo a cargo de uno de nuestros Padres Dominicos»: $R$. Triana a Jordana, 3-5-1938, en AMAE, R$1004 / 8$.

${ }^{33}$ La primera «embajada cultural» desembarcó en septiembre de 1937 con actos en Argentina, Chile, Uruguay, Perú y Brasil. La segunda se desarrolló en los mismos paises desde diciembre de 1937 a febrero de 1938, con parecidos protagonistas. Entre ellos destacaron: E. Montes, F. Valls (jurista e historiador), Peiró (religioso y doctor en teología), Ibáñez Martín (doctor en derecho, filosofía y letras, cofundador de Acción Española) y la participación ocasional de E. Marquina, J. Calvo Sotelo y los jefes falangistas locales: AMAE, R$1318 / 20$. 
truyendo en la península como soporte legitimador del régimen. Así lo evidenciaban tanto los argumentos esgrimidos de "Cruzada católica", anticomunista y de «orden»; como los sectores sociales que se pretendía captar y movilizar; esto es, las élites socio-políticas y los católicos.

Retomaban esquemas conservadores e historicistas -en la línea de Menéndez Pelayo - que organizaban la historia patria en torno al periodo de la España creadora de los siglos de Oro. La idea Imperial y la Catolicidad hacian posible el engarce del Nuevo Estado con un período histórico por cuya redención y continuación se aseguraba luchar. La conquista de América era "la sintesis de la dinámica histórica nacional», por cuanto constituía el paradigma de la perfecta identificación entre misión patriótica y religión ${ }^{34}$. Si de cara a la opinión pública interior, esta recuperación de la tradición histórica de España posibilitaba la revalorización de una sociedad jerárquica y corporativa ${ }^{35}$; hacia el exterior, la España nacionalista se mostraba al mundo como el baluarte de los valores eternos de la civilización occidental: "orden y religión». La ideología quedaba envuelta en ropajes historicistas y culturales, obviando cualquier alusión que pudiera llevar a la confusión con modelos fascistas internacionales.

El Alzamiento tenía un signo reintegrador de los «valores y esencias auténticamente españolas». Los oradores unían el proselitismo político al gran reclamo legitimador de la españolidad intrínseca del bando que representaban, frente a la «desespañolización» de los «rojos» bolchevizados e internacionalistas. Apartarse de la tradición histórica española abocaba a todos los pueblos hispánicos al caos comunista y a la desintegración nacional: especialmente si eran los intelectuales quienes iniciaban

${ }^{34}$ Sobre la amalgama ideológica que constituye el concepto nacionalista de «Hispanidad" a partir de las aportaciones fascistas y de grupos de la derecha más tradicional: MoRODo, R., Acción Española. Origenes ideológicos del franquismo. Madrid 1980, págs. 149-168; Egıdo, A., "La Hispanidad en el pensamiento reaccionario español de los años Treinta» en Coloquio sobre Proyección Mediterránea y Proyección Atlántica de la España Contemporánea. Madrid, Universidad Complutense, 1988 (en prensa); Delgado Gómez-Escalonilla, L., Diplomacia Franquista y Politica Cultural hacia Iberoamérica, 1939-1953. Madrid 1988, págs. 26-36; GonzÁlez, E., Limón, F., op. cit., págs. 11-30.

${ }_{35}$ VALLS MONTES, R., La interpretación de la Historia de España y sus orígenes ideológicos en el bachillerato franquista, (1938-1953). Valencia 1983, págs. 54-81; GonzÁlez, E., Limón, F. op. cit, págs. 31-45. También en ALTED VIGiL, A., Política del Nuevo Estado sobre el patrimonio cultural y la educación durante la Guerra Civil española. Madrid 1984, págs.149-150. Para la evolución ideológica inmediatamente posterior: Díaz, Elías, Notas para una historia del pensamiento español actual, (1939-1973). Madrid 1974. Ramirez, Manuel y otros, Las fuentes ideológicas de un Régimen (España, 1939-1945). Zaragoza 1978. Ramírez, Manuel, España 1939-1975 (Régimen político e ideología). Barcelona 1978. 
el camino del desviacionismo ${ }^{36}$. Este tipo de mensaje iba ciertamente dirigido a las "élites" hispanoamericanas que durante los años veinte y treinta habian apostado por el "Hispanoamericanismo". Intelectuales conservadores y reaccionarios que, en conjunto, consideraron tal corriente como la ideología más adecuada para responder a la amenaza norteamericana y de la izquierda. Dicho fenómeno se había producido en casi todas las repúblicas hispanoamericanas, captando a grupos de intelectuales minoritarios, pero influyentes: José de la Riva Agüero, Felipe Barreda Laos, Felipe Sassone, Víctor A. Belaúnde o A. Wagner de Reyna (Perú); P. A. Cuadra (Nicaragua); J. M. Velasco Ibarra (Ecuador); Luis Alberto Herrera (Uruguay); Osvaldo Lira, V. Valdivia y Jaime Eizaguirre (Chile), etc. ${ }^{37}$. Por otra parte, el reclamo propagandístico de la «Cruzada» proporcionó un arma fundamental a la hora de convencer a los católicos. Cabe pensar que el fervor político de éstos se apartara poco de las actitudes manifestadas, casi sin excepción, por sus jerarquías eclesiásticas.

La opción elegida por los decisores nacionalistas no incluía la propaganda de masas. Las convocatorias franquistas no tuvieron casi nunca el carácter masivo de los mítines republicanos. Las instrucciones de Burgos eran ceñirse a relaciones políticas y estríctamente diplomáticos, actuar cerca de las personalidades (gubernamentales, militares, jurídicas, parlamentarias o eclesiásticas) que se intuía más próximas ideológicamente, dejando la propaganda efectiva sobre los "enemigos" para después de la guerra, cuando se contara con suficientes medios económicos. "Atraerse a los de calidad y riqueza» fue la máxima habitual; no sólo referida a la colonia española, sino al resto de las sociedades anfitrionas ${ }^{38}$.

La falta de reconocimiento diplomático pudo reforzar semejantes tendencias. La prudencia recomendada desde Burgos impidió la participación oficial de los nacionalistas en los actos públicos de los partidos conservadores que les apoyaban: bien fuera para evitar polémicas que hubiesen perjudicado el precario régimen juridico de los representantes

\footnotetext{
${ }^{36}$ Los títulos de las conferencias son significativos: «El sentido de la Patria a través de la Historia de España», "Renacimiento religioso en España", "Orígenes del Nacionalismo Español», "Derecho medieval español», "La mezquita de Córdoba», "Franco», "Vocación y destino de España», "El mundo hacia el abismo», "España, puente sobre el abismo», etc., en AMAE, R-1318/20.

${ }^{37}$ Vid. RoJas Mix, Manuel, «El Hispanismo. Ideología de la dictadura en Hispanoamérica", en Araucaria, n. ${ }^{\circ} 2$ (1978), págs. 47-59 y MAINER, J. C., «Un capitulo regeneracionista: el hispanoamericanismo (1892-1923)", en De la crisis del Antiguo Régimen al franquismo, VII Coloquio de Pau. Madrid 1977; QuIJADA, M., op. cit., pág. 428.

${ }^{38}$ Los Jefes de Sección a Jordana, enero de 1939, AMAE, R-834/33.
} 
oficiosos o, quizás, por el convencimiento de representar en América una España eterna, por encima de banderias políticas.

El resultado de esta política propagandística produjo resultados desiguales. Teniendo en cuenta el clima político del momento, es evidente que las imágenes de defensa de la religión y el orden contra el terror comunista, proporcionaron aliados naturales muy poderosos en las más altas esferas de los gobiernos lationamericanos, entre las autoridades locales y ante las jerarquías eclesiásticas. Este hecho se materializó en un amplio apoyo al bando «nacional» por parte de las instancias citadas, que nada tenía que ver con la aparente «neutralidad» legal esgrimida en el tema del reconocimiento de Franco. Sobre todo en aquellas naciones con regimenes de fuerza y sociedades civiles muy controladas desde los aparatos de poder. Por el contrario, los propios agentes diplomáticos franquistas reconocieron que la popularidad del Nuevo Estado entre los sectores mayoritarios de la opinión pública de América Latina no podia ser más baja en 1939 .

La política cultural no hizo sino reforzar esta situación y reproducir algunas pautas manifestadas en la propaganda bélica. Se confiaba en que la España Nacional pudiera convertirse en uno de los «luminares de la transformación próxima» de la civilización occidental, investida de un aura de prestigio cultural y espiritual nueva. Como antes de 1936, se buscaba ofrecer un producto cultural atractivo para las élites intelectuales, al objeto de prestigiar la imagen de España y favorecer, de esta forma, las relaciones políticas; siempre con miras a la constitución de un área de influencia cultural y política en América que pudiera ser utilizada en cualquier proyecto de política exterior.

La presentación y el lanzamiento exterior de estas ideas que iban a presidir las acciones culturales del Nuevo Estado fueron expuestas en enero de 1938 por Jordana y Sainz Rodriguez en el acto de jura y constitución del «Instituto de España» en Salamanca ${ }^{39}$. Durante la guerra, sólo se llegaron a erigir las bases institucionales de tales planteamientos. Para ello, se restableció una Sección de Relaciones Culturales en el Ministerio de Asuntos Exteriores; la Junta de Relaciones Culturales y una Sección de Hispanismo e Hispanización dependiente del Ministerio de Educación. En el seno de la Junta se soñó con la celebración de un gran congreso de intelectuales europeos y americanos; la creación de un doctorado Hispanoamericano; la política de atracción de estudiantes hispa-

${ }^{39}$ ABC, (Sevilla), 7-1-1938. Curiosamente, los oradores fueron el General Gómez Jordana y el vicepresidente del Instituto, Pedro Sáinz Rodríguez (sin cargos ministeriales en ese momento). Sobre la fundación del Instituto: Alted VIGiL, A., Op. cit., págs. 239-241. 
noamericanos hacia universidades españolas; la creación de institutos hispánicos donde convivieran estudiantes hispanoamericanos o la elaboración de «un repertorio bibliográfico con la catalogación de toda producción literaria y artística en lengua española, lo que transformaría a nuestro país en el receptáculo central de las actividades de espíritu de veintidós estados distintos», etc. ${ }^{40}$ Sin embargo, la materialización efectiva de tan ambiciosas proclamas fue muy pobre entre 1936 y 1939. Las constricciones bélicas desviaban la atención política inmediata hacia la colaboración con las naciones aliadas; mientras que la polémica de la opinión hispanoamericana no tenía una trascendencia inmediata. Ni siquiera era posible restablecer relaciones culturales con naciones que no habian reconocido oficialmente al gobierno. Con el agravante de que hasta junio de 1939 no se distribuyó la exigua subvención asignada a la expansión cultural en el extranjero ${ }^{41}$.

El proyecto de Sainz Rodríguez era coherente y agresivo, en la línea de los reiterados planes de Expansión Cultural elaborados a lo largo del primer tercio de siglo, que pretendian hacer de España un foco de cultura y prestigio hacia América. También era coherente el equipo de hombres encargado de ponerlo en marcha: conservadores y monárquicos procedentes o cercanos a Acción Española, instalados en el Ministerio de Educación e incluso en Exteriores. Sin embargo, en aquellos primeros años la diplomacia cultural no se contaba entre las prioridades de la cancilleria española. Al final de la Guerra, casi todos los protagonistas de la gestación del proyecto fueron relevados: Sáinz Rodríguez fue sustituído por Ibáñez Martín, Jordana por Beigbeder, Sangróniz fue destinado a Venezuela, Teixidor (Jefe de la Sección de Culturales) a Roma y Pujadas fue cesado como Jefe de Ultramar. Posiblemente la dispersión de los monárquicos desde esas fechas, la guerra particular de Serrano Súñer contra

${ }^{40}$ Orden del día de la sesión que ha de celebrar la Junta de Relaciones Culturales en la ciudad de Burgos el dia 23 de Abril de 1938, en AMAE, R-1380/25. Y se puede decir que otro tanto ocurrió con las proyecciones del Ministerio de Educación en su Sección de Hispanismo e Hispanización y del Instituto de España, encargado de preparar un doctorado hispanoamericano en el "Colegio de la Españas»: Alted, A., Op. cit., pág. 132 y 242.

${ }^{41}$ Boletín Oficial de la JDNE, (Burgos) 2-3-1938. NIÑo, A., «L'expansion culturelle espagnole en Amérique hispanique (1891-1936), en Relations Internationales, n. 50 (1987), págs 197-213. Delgado, L., Op. cit, págs. 39-41; Alted, A., Op. cit., 111-116. También AMAE, R1380/25. El único acuerdo efectivo relacionado con América fue la solicitud a Hacienda de un crédito de 25.000 pesetas con cargo al presupuesto de la sección, destinado a la adquisición de un fondo de libros que «se distribuirian con fines de propaganda de nuestra cultura en el extranjero y especialmente en Hispanoamérica». El grueso de la actividad se habia orientado hacia el hermanamiento con Portugal, Italia y Alemania); Resumen de las actividades de la Sección de Relaciones Culturales durante el primer año de gobierno nacional. Enero de 1939, en AMAE, R-1380/25. Sobre el presupuesto: BOE, (Burgos) 18-6-1939. 
el grupo y la ascendente influencia de FET y de las JONS no fueron factores ajenos a tales cambios. Si bien las iniciativas franquistas de diplomacia cultural franquista que se se pusieron en marcha hasta 1945 apenas iban a diferir de aquellos primeros planteamientos de 1938 .

\section{LAS GESTIONES DIPLOMÁTICAS}

Los representantes diplomáticos franquistas eran conscientes de los factores que influian en la toma de posición de las repúblicas americanas respecto al conflicto español: los debates de política interior y la influencia norteamericana; pero conocían perfectamente la proclividad de parte de los medios oficiales latinoamericanos hacia el bando nacionalista. Su estrategia fue, por tanto, alimentar las simpatías de los círculos gubernamentales persiguiendo el reconocimiento. En los primeros meses de la guerra, se buscó la necesaria benevolencia de las autoridades americanas que permitiera la actividad de los agentes oficiosos. Poco a poco, se laboró con vistas al intercambio de agentes, o al menos, en busca de un reconocimiento de facto que permitiera el restablecimiento de las relaciones comerciales y de los intercambios políticos básicos. Finalmente, a partir de 1938, cuando la victoria se sabía segura, sólo se aceptó el reconocimiento «de jure» y a él se supeditaron el resto de las conexiones, incluirias las económicas.

Es posible un breve repaso a lo que fue la actividad diplomática en torno a la Guerra Civil ${ }^{42}$. En agosto de 1936, el gobierno uruguayo -pronacionalista - lanzaba un llamamiento para una mediación americana en la guerra, sin éxito. En aquellos meses, Argentina intentaba capitalizar las iniciativas latinoamericanas convocando reuniones de los embajadores americanos acreditados en España al objeto de defender el ejercicio del asilo politico. Curiosamente, ninguna nación americana fue invitada a participar en el Comité de No-Intervención. Desde la SDN sólo el representante mexicano condenó el acuerdo, frente a la actitud de inhibición del canciller argentino, Saavedra Lamas, entonces presidente.

En noviembre, tres dictaduras militares «Salvador, Nicaragua y Guatemala» reconocieron a los rebeides: en parte por la creencia de que la

\footnotetext{
${ }^{42}$ Para las referencias documentales de este apartado ver: PARDo SANZ, R. M., La Guerra Civil en América Latina. Política y diplomacia nacionalista. Memoria de Licenciatura, UNED, 1989.
} 
caída de Madrid era inminente. A pesar del reconocimiento, no acreditaron representantes, en vista de la actitud norteamericana. Un mes después, se inauguraba la Conferencia Interamericana de Buenos Aires; donde, por iniciativa costarricense, se discutió la posibilidad de una mediación. El resultado fue una declaración «por la paz de España» y un minuto de silencio: solución que armonizaba con la línea neutralista estadounidense y contribuía a la imagen de cooperación panamericana.

México emprendió un tercer intento de mediación americana en abril de 1937, sin éxito. En la SDN hacía un llamamiento para el fin de la no intervención que sólo apoyó Colombia. Durante el verano, fracasaba la petición uruguaya de reconocer colectivamente la beligerancia de los dos bandos. En septiembre de 1937, la inhibición latinoamericana evitó la reelección de España (republicana) como miembro del Consejo de la Liga de Naciones: sólo México, Colombia y Ecuador votaron a favor. Un mes después, en Octubre de 1937, se repitió una tentativa de buenos oficios por iniciativa cubana que no tuvo éxito. La mayoría de los países desestimaron la propuesta invocando el principio de neutralidad y no intervención.

A principios de 1938 se consiguió que Uruguay y Chile reconocieran agentes oficiosos de Burgos (como habian hecho otras naciones europeas). Otros paises arnericanos intentaron acuerdos de ese tipo sin éxito, una vez que Burgos decidió que ese tipo de reconocimiento no interesaba. Al fin varios de los paises que deseaban reconocer oficiosamente por razones económicas (Cuba, Venezuela y Brasil) o ideológicas optaron por esperar a la Conferencia Panamericana en diciembre de 1938, con la expectativa de llegar a algún acuerdo continental que permitiera proceder al reconocimiento «de jure» sin tener que enfrentar problemas con sus opiniones públicas internas radicalmente antifranquistas. En la conferencia, celebrada en Lima, México tomó la iniciativa y propuso una gestión de buenos oficios entre los contendientes: sólo Haití, México y Cuba se mostraron dispuestos a colaborar. Se concluyó acordar plena libertad para proceder al reconocimiento de! gobierno de Franco. A pocos meses de la victoria, era el espaldarazo definitivo del bloque americano para los nacionalistas españoles.

En febrero de 1939, tras la caída de Cataluña, efectuaron su reconocimiento oficial Perú, Uruguay, Venezuela y Bolivia. Argentina esperó a que lo hicieran Gran Bretaña y Francia, el día 27 del mismo mes. El resto de las repúblicas aguardaron a la conclusión de la contienda: lo hicieron primero Brasil y Paraguay. Desde el dos de abril procedieron también: Ecuador, Colombia, Chile, Haití, Rep. Dominicana, Costa Rica y Honduras. Posteriormente, en mayo se obtuvo el reconocimiento de Panamá y un 
mes después se acordó un precario arreglo con Cuba. México nunca normalizaría sus relaciones con el régimen de Franco.

Ninguna república centroamericana (exceptuadas aquellas que lo habían hecho en noviembre de 1936) ni caribeña efectuó su reconocimiento antes que Estados Unidos (4 de marzo de 1939). Más, la voluntad de plegarse a las directrices estadounidenses - lógica para aquellas repúblicas incluidas en el glacis de influencia - también funcionó en el caso de algunas dictaduras (Vargas en Brasil o Batista desde Cuba) que perseguían el apoyo de Washington como elemento definitivo de legitimación. Para lograrlo, intentaban maquillar sus regímenes con apariencias democráticas y perseguian la unanimidad con EEUU en las líneas de política exterior, alentando las iniciativas panamericanas. En este sentido, el «antifascismo» - materializado en una defensa legalista de la República Española- se constituyó, en una baza política poco onerosa para tales regímenes durante los años del conflicto hispano, pues permitía mostrar una supuesta homología respecto a Estados Unidos, a pesar de la abierta dualidad con lo que era la politica interior ${ }^{43}$.

En general, casi todos los paises americanos ampliaron los ecos de la "Good Neighbour Policy». La mayoría, buscaba el apoyo económico político de Washington; aunque se utilizaban los argumentos del discurso panamericanista rooseveltiano que insistía en la voluntad de evitar el contagio de la crisis europea a partir de un difuso proyecto de coordinación continental americana. Sin embargo, existió un tremendo contraste entre la política neutral aureada por las cancillerías con respecto al tema formal del reconocimiento y las actitudes de las diversas autoridades civiles (estatales y aun locales). La permisibilidad otorgada a los nacionalistas españoles en la difusión de su propaganda y el constante entorpecimieto a la actividad republicana así lo testimonian.

Por otra parte, al natural fenómeno de «empatía» ideológica que presidió las reacciones oficiales ante guerra española, se superpuso «la

43 De hecho, la ambigua relación del Departamento de Estado con algunas dictaduras latinoamericanas constituía una de las paradojas de la politica de Buena Vecindad. Como señalaba uno de los representantes nacionalistas en 1938: «Existe una contradicción entre la política exterior de la mayor parte de las Naciones de América, arrastrada por la influencia politica y económica de los Estados Unidos, con las mentiras convencionales del panamericanismo de dibujar horizontes de amplia democracia; y los intereses de la política interna de cada nación, que los obliga a sostener gobiernos de orden y fuerza, en realidad dictaduras, bajo la etiqueta de democracias teóricas". («A. Pinilla a Jordana, 11-9-1938»: AMAE, R-1449/3). WELLES, Sumner, «The New Era in Pan American Relations", en Foreign Affairs, vol. 15, n. 3 (1937), pág. 446; Nerval, Nerval (Seud.): «Europe versus the United States in Latin America», en Foreign Affairs, vol 15, n. 4 (julio 1937), págs. 636-645. 
preeminencia del conflicto politico interno» de cada país. El temor a las reacciones violentas de vastos sectores de la opinión y de la oposición política moderó las actitudes partidistas de algunos regímenes; en especial cuando se aproximaban campañas electorales. El debate ideológico en torno a la cuestión hispana formó parte de la lucha política interna en cada una de las repúblicas latinoamericanas. Esto ocurrió en el caso de Cuba, Brasil e incluso México. Batista utilizó la defensa de la república española como campo de acción privilegiado para su nueva politica de acercamiento a los comunistas; a Vargas le sirvió cuando buscaba el desmarque del integralismo. Las actitudes de condena a los «facciosos» españoles proporcionaron a sus respectivos regímenes una pátina de democratismo o al menos de antifascismo. En el caso mexicano, el gobierno de Cárdenas encontró una vía de acción común para laborar con la izquerda (Confederación de Trabajadores Mexicanos y el partido comunista).

Las informaciones remitidas por los representantes oficiosos acreditados en América confirman estos postulados para muchos otros países. En Panamá, Arenzana resaltaba la colaboración de elementos izquierdistas panameños (socialistas y comunistas) con republicanos españoles en las campañas locales contra el gobierno de Arosemena. Sangróniz, desde Venezuela, achacaba la frialdad oficial al temor a provocar dificultades con la oposición de izquierdas, a pesar de las simpatías gubernamentales hacia Franco. Si en 1937 el gobierno conservador argentino no dio ningún paso para normalizar jurídicamente las relaciones fue, entre otros motivos, porque cualquier compromiso hubiese desagradado al partido radical (pro-republicano) con el que pretendía formar gobierno en próximas elecciones, y por «miedo a una opinión pública muy dividida por el tema español».

En esta misma línea, las convocatorias a beneficio de la república española enmascaraban demostraciones de los partidos de oposición. En Ecuador o Uruguay, los agentes nacionalistas condenaban el aprovechamiento de ese tipo de actos para compenetrar a socialistas, comunistas y otros grupos de la vanguardia revolucionaria; mientras que los componentes del gobierno simpatizantes con la «Causa» mantenían colectivamente una actitud de reserva. La ayuda a la república fue, por ejemplo, bandera común para los partidos que componian el Frente Popular chileno ${ }^{44}$.

44 «Arenzana a Muguiro, 3-6-1937» en AMAE, R-1005/7; «Sangróniz a Jordana, 13-2-1939» en AMAE, R-1005/17; «J. Tibau a Jordana, 3-3-38» en AMAE R-1003/4. En Argentina: «F. Amat a Francisco Serrat, 2-2-1937» en AMAE R-1003/0; «J. P. Lojendio a Jordana, 9-2-1938» en 
En el caso de la pasividad del gobierno colombiano, la iglesia y el poderoso partido Conservador se pronunciaron desde 1936 a favor de Franco, compeliendo a los liberales a no pasar del apoyo verbal a la república, a riesgo de enajenarse gran parte de la opinión pública. De igual modo, Cárdenas hubo de suavizar algunas actitudes ante el apremio de una sección influyente de la sociedad mexicana. En ambos países una parte importante de la opinión no estuvo muy de acuerdo con la línea oficial marcada por sus respectivos gobiernos ${ }^{45}$.

En conjunto, América Latina tendió a ver el conflicto español bajo el prisma de sus propios problemas domésticos. Como señalaba E. Gil en 1937, la crisis española suscitó el temor en las incipientes democracias latinoamericanas, dado que el ejército podía imitar el prototipo golpista español -en México esta percepción no era tan descabellada-; de la misma forma que las pautas de la izquierda peninsular pudieron estremecer a los sectores de la derecha americana ${ }^{46}$. Lo que estaba sucediendo en España servia para clarificar y agudizar las cuestiones políticosociales a las que se enfrentaban sus propios pueblos; y finalmente, como el ejemplo que era preciso evitar en muchos sentidos.

\section{ALGUNAS CONCLUSIONES}

La primera observación que se percibe al estudiar el tema es el contraste entre la conmoción que la guerra provocó al otro lado del Atlántico y la insignificancia de esa región geográfica para las autoridades de Burgos. Un área, sobre todo, donde no se dirimían cuestiones como el abastecimiento bélico ni apoyos diplomáticos fundamentales.

Por otra parte, América se configura como un marco privilegiado para ver la interrelación entre los desarrollos políticos internos y la acción ex-

AMAE, R-1002/14. Incluso el embajador republicano reconoce en las manifestaciones de adhesión del nuevo gobierno argentino hacia su persona signos del acercamiento hacia los radicales: «Angel Ossorio a José Girai, 6-10-1938» en AMAE, R-2571/53. Asimismo, desde Santiago, T. Súñer lamentaba que el peso de la oposición izquierdista y la proximidad de las elecciones impidieran cualquier mejora de las relaciones con Chile: «la propaganda roja aparece ligada a personalidades marxistas chilenas que encauzan los actos a fin de realizar propaganda política nacional»: «T. Súñer a Jordana, 15-11-1938» en AMAE, R-1006/11. Para Uruguay: «R. Soriano a Jordana, 19-4-1938» en AMAE, R-1005/15.

${ }_{45}$ Busnell, D., Art. cit., págs.167-8 y Powell, T., op. cit., págs. 110-116.

${ }^{46}$ GlL, Enrique, "Repercussions of the Spanish Crisis in Latin America», en Foreign Affairs, vol.1 5, n. ${ }^{\circ} 3$, (abril 1937), págs. 547-548. 
terior del embrión de estado que constituía el primer gobierno franquista. En la puesta en marcha de la actividad americana se dan cita procesos como la formación de un aparato diplomático leal; el trasvase a América de la pugna interna de fuerzas políticas que constituyó la «Unificación» de abril de 1937, con la implantación de Falange Exterior; y, por fin, el anuncio en aquel continente del modelo cultural nacionalista con sus claves de «Hispanidad".

La operatividad de los instrumentos que se pusieron en marcha varia según se consideren los objetivos a corto y a largo plazo. En el primer caso, la relación con el elemento oficial y la oligarquía americana fue adecuada si se juzga el clima político allí existente. De hecho, contribuyó en gran medida a entorpecer la actividad republicana; si bien en el tema de los reconocimientos oficiales se pudo hacer poco y hubo que esperar hasta 1939.

América quedó como un proyecto de futuro para el régimen: tanto por lo que se refiere a los planes falangistas respecto a las colonias españolas; como en el tema de la posible expansión políticacultural de España en América elaborado por círculos próximos a Acción Española. En tales objetivos de largo plazo, hubo una percepción desacertada acerca de las posibilidades de España en América, producto no sólo de la ideología del bando nacionalista, sino también de pervivencias simbólicas de toda una mentalidad colectiva. El menosprecio hacia la opinión pública general (extensible incluso a la colonias de emigrantes) y la confianza en la capacidad española de irradiar cultura e influencia intelectual, política y social pudieron dar hálito a construcciones irreales para los años del conflicto mundial.

Por fin, la Guerra Civil española provocó serias rupturas en relación con Latinoamérica. Se produjeron incidentes políticos graves que enfriaron las relaciones con algunos países durante años. El caso de México fue paradigmático; mas, es imposible obviar las tensiones con Chile por la cuestión del asilo político, los ccnflictos con Cuba por la indemnización del «Manuel Arnús", etc. Como graves fueron, asimismo, los quebrantos en el capítulo de las relaciones económicas (cuando estaban pendientes de negociación multitud de convenios comerciales) y lo mismo ocurrió con los intercambios culturales.

Ahora bien, tal vez la consecuencia más terrible fue la quiebra que sufrió la imagen de España de cara a la opinión pública latinoamericana. En parte - se ha apuntado- porque la guerra sacaba a España del marco intemporal en que había estado colocada durante años, para dejarla inmersa en los duelos políticos europeos y mundiales. Pero, sobre todo, por el resultado de la batalla de la propaganda, reforzada luego por la 
presencia del exilio republicano en muchos paises. Elementos, todos, que dejaron el terreno abonado para que prendiera la propaganda norteamericana contra el Eje, cuyas salpicaduras llegaron hasta Falange (y por extensión hasta el régimen) dañando por muchos años las posibilidades españolas en la región. 